\title{
Radiative and climate impacts of a large volcanic eruption during stratospheric sulfur geoengineering
}

\author{
A. Laakso ${ }^{1}$, H. Kokkola ${ }^{1}$, A.-I. Partanen ${ }^{2,3}$, U. Niemeier ${ }^{4}$, C. Timmreck ${ }^{4}$, K. E. J. Lehtinen ${ }^{1,5}$, H. Hakkarainen ${ }^{6}$, and \\ H. Korhonen ${ }^{2}$ \\ ${ }^{1}$ Finnish Meteorological Institute, Atmospheric Research Centre of Eastern Finland, Kuopio, Finland \\ ${ }^{2}$ Finnish Meteorological Institute, Climate Research, Helsinki, Finland \\ ${ }^{3}$ Department of Geography, Planning and Environment, Concordia University, Montréal, Québec, Canada \\ ${ }^{4}$ Max Planck Institute for Meteorology, Hamburg, Germany \\ ${ }^{5}$ Department of Applied Physics, University of Eastern Finland, Kuopio campus, Kuopio, Finland \\ ${ }^{6}$ A. I. Virtanen Institute for Molecular Sciences, University of Eastern Finland, Kuopio, Finland
}

Correspondence to: A. Laakso (anton.laakso@fmi.fi)

Received: 18 June 2015 - Published in Atmos. Chem. Phys. Discuss.: 12 August 2015

Revised: 21 December 2015 - Accepted: 22 December 2015 - Published: 18 January 2016

\begin{abstract}
Both explosive volcanic eruptions, which emit sulfur dioxide into the stratosphere, and stratospheric geoengineering via sulfur injections can potentially cool the climate by increasing the amount of scattering particles in the atmosphere. Here we employ a global aerosol-climate model and an Earth system model to study the radiative and climate changes occurring after an erupting volcano during solar radiation management (SRM). According to our simulations the radiative impacts of the eruption and SRM are not additive and the radiative effects and climate changes occurring after the eruption depend strongly on whether SRM is continued or suspended after the eruption. In the former case, the peak burden of the additional stratospheric sulfate as well as changes in global mean precipitation are fairly similar regardless of whether the eruption takes place in a SRM or nonSRM world. However, the maximum increase in the global mean radiative forcing caused by the eruption is approximately $21 \%$ lower compared to a case when the eruption occurs in an unperturbed atmosphere. In addition, the recovery of the stratospheric sulfur burden and radiative forcing is significantly faster after the eruption, because the eruption during the SRM leads to a smaller number and larger sulfate particles compared to the eruption in a non-SRM world. On the other hand, if SRM is suspended immediately after the eruption, the peak increase in global forcing caused by the eruption is about $32 \%$ lower compared to a corresponding eruption into a clean background atmosphere. In this sim-
\end{abstract}

ulation, only about one-third of the global ensemble-mean cooling occurs after the eruption, compared to that occurring after an eruption under unperturbed atmospheric conditions. Furthermore, the global cooling signal is seen only for the 12 months after the eruption in the former scenario compared to over 40 months in the latter. In terms of global precipitation rate, we obtain a $36 \%$ smaller decrease in the first year after the eruption and again a clearly faster recovery in the concurrent eruption and SRM scenario, which is suspended after the eruption. We also found that an explosive eruption could lead to significantly different regional climate responses depending on whether it takes place during geoengineering or into an unperturbed background atmosphere. Our results imply that observations from previous large eruptions, such as Mount Pinatubo in 1991, are not directly applicable when estimating the potential consequences of a volcanic eruption during stratospheric geoengineering.

\section{Introduction}

Solar radiation management (SRM) by injecting sulfur to the stratosphere is one of the most discussed geoengineering methods, because it has been suggested to be affordable and effective and its impacts have been thought to be predictable based on volcanic eruptions (Crutzen, 2006; Rasch et al., 2008; Robock et al., 2009; McClellan et al., 2012). 
Stratospheric sulfur injections could be seen as an analogue of explosive volcanic eruptions, during which large amounts of sulfur dioxide $\left(\mathrm{SO}_{2}\right)$ are released into the stratosphere. Once released, $\mathrm{SO}_{2}$ oxidizes and forms aqueous sulfuric acid particles which can grow to large enough sizes (some hundreds of nanometres) to efficiently reflect incoming solar radiation back to space. In the stratosphere, the lifetime of the sulfate particles is much longer (approximately 1-2 years) than in the troposphere, and the cooling effect from sulfate aerosols may last for several years, as has been observed after large volcanic eruptions, such as Mount Pinatubo in 1991 (Hansen et al., 1992; Robock, 2000; Stenchikov et al., 2009). Stratospheric SRM would maintain a similar aerosol layer in the stratosphere continuously and could therefore be used (at least in theory) as a means to buy time for the greenhouse gas emission reductions (Keith and MacMartin, 2015).

One concern in implementing stratospheric SRM is that an explosive eruption could happen while SRM is being deployed. While it is impossible to predict the timing of such eruptions, large volcanic events are fairly frequent with three eruptions in the 20th century suggested having volcanic explosivity index (VEI) value of 6, indicating substantial stratospheric injections (Santa María in 1902, Novarupta/Katmai in 1912, and Pinatubo in 1991) (Robock, 2000). Thus it is possible that a large volcanic eruption could happen during SRM deployment, which would most likely be ongoing for decades. Should this happen, it could lead temporarily to a very strong global cooling effect when sulfate particles from both SRM and the volcanic eruption would reflect solar radiation back to space. While the climate effects of volcanic eruptions into an unperturbed atmosphere have been investigated in many previous studies (see overview papers by Robock, 2000, and Timmreck, 2012), they may be different if a volcanic eruption took place during SRM. In the unperturbed atmospheric conditions, the stratosphere is almost clean of particles, while during SRM there would already be a large amount of sulfate in the stratosphere prior to the eruption. Thus, the temporal development of the volcanic aerosol size distribution and related to this the volcanic radiative forcing under SRM conditions may behave very differently.

Here we study the effects of a volcanic eruption during SRM by using two Max Planck Institute models - i.e. the general circulation model (GCM) MAECHAM5 (Giorgetta et al., 2006) coupled to an aerosol microphysical module HAM-SALSA (Bergman et al., 2012; Kokkola et al., 2008), and the Max Planck Institute Earth System Model (MPIESM) (Giorgetta et al., 2013). We investigate the simulated characteristics of the stratospheric sulfur burden, radiative forcing, and global and regional climate effects.

\section{Methods}

\subsection{Model descriptions}

The simulations were performed in two steps. In the first step, we used the aerosol-climate model MAECHAM5-HAMSALSA to define global aerosol fields in scenarios with stratospheric sulfur injections and/or a volcanic eruption. In the second step, we prescribe the simulated stratospheric aerosol fields from MAECHAM5-HAM-SALSA to MPIESM, similar to Timmreck et al. (2010).

\subsubsection{Defining aerosol fields with MAECHAM5-HAM-SALSA}

For the global aerosol simulation we use MAECHAM5HAM-SALSA. The atmospheric model MAECHAM5 is a middle atmosphere configuration of ECHAM5, in which the atmosphere is divided into 47 height levels reaching up to $\sim 80 \mathrm{~km}$. MAECHAM5 is integrated with a spectral truncation of 63 (T63), which corresponds approximately to a $1.9^{\circ} \times 1.9^{\circ}$ horizontal grid. The simulations were performed with a time step of $600 \mathrm{~s}$.

The aerosol module HAM is coupled interactively to MAECHAM5 and it calculates aerosol emissions and removal, gas and liquid phase chemistry, and radiative properties for the major global aerosol compounds of sulfate, organic carbon, black carbon, sea salt and mineral dust.

In the original ECHAM-HAM (Stier et al., 2005), the aerosol size distribution is described with seven lognormal particle modes with fixed standard deviations and is designed to represent the tropospheric aerosol conditions. Therefore, the width of the coarse mode is optimized for description of sea salt and dust particles, and it does not perform well in special cases like volcanic eruptions or SRM, when a fairly monodisperse coarse mode of sulfate particles can form in the stratosphere (Kokkola et al., 2009). Simulating stratospheric aerosols would then require narrower coarse mode (see e.g. Niemeier et al., 2009) which on the other hand is not appropriate for simulating tropospheric aerosols. Here we chose to use a sectional aerosol model SALSA (Kokkola et al., 2008), which has been previously implemented with ECHAM-HAM (Bergman et al., 2012) and is used to calculate the microphysical processes of nucleation, condensation, coagulation and hydration. SALSA does not restrict the shape of the size distribution making it possible to simulate both tropospheric and stratospheric aerosols with the same aerosol model.

The default SALSA setup divides the aerosol number and volume size distribution into 10 size sections, which are grouped into three subregions (Fig. 1, left-hand panel, distribution a). In addition, it has 10 extra size sections to describe external mixing of the particles (Fig. 1, left hand panel, distributions $b$ and $c$ ). In order to keep the number of tracer variables to the minimum, in the third subregion (coarse par- 


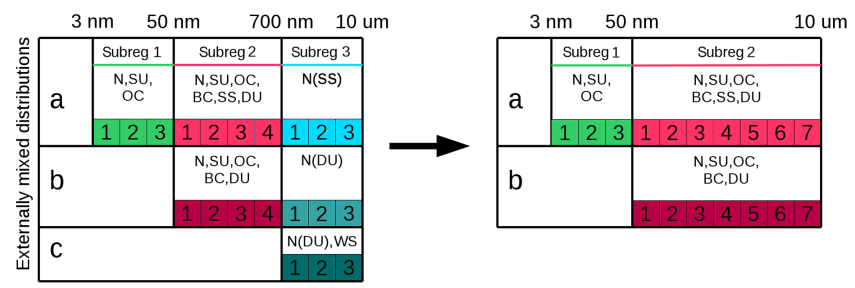

Figure 1. Particle size sections and chemical species in aerosol model SALSA. The left-hand panel illustrates the standard SALSA set-up. The rows "a", "b" and "c" denote the externally mixed particle distributions. Within each distribution and subregion, $\mathrm{N}$ denotes number concentration and SU, OC, BC, SS and DU respectively sulfate, organic carbon, black carbon, sea salt and dust masses, which are traced separately. Within distributions " $a$ " and " $b$ " in subregion 3, only particle number concentration is tracked, and all particles are assumed to be sea salt in distribution "a" (N(SS)) and dust in distribution "b" $(\mathrm{N}(\mathrm{DU}))$. In distribution "c" only number concentration (N(DU)) and water soluble fraction (WS) are traced. The numbers at the bottom of each subregion illustrate the size sections within that subregion. In our study, the third subregion is excluded and the second subregion is broadened to cover subregion 3 size sections (right-hand panel).

ticles) only a number concentration in each section is tracked and thus the particle dry size is prescribed. This means that the sulfate mass is not explicitly tracked in this region although it is allowed to change the solubility of the dust particles (distribution c in Fig. 1). In addition, there is no coagulation and condensation growth inside this third subregion, although smaller particles and gas molecules can be depleted due to collisions with particles in subregion 3. In standard tropospheric conditions, this kind of description of the coarse particles is sufficient and it saves computational time and resources. However, when studying large volcanic eruptions or stratospheric sulfur geoengineering, microphysical processing of an aerosol by a large amount of stratospheric sulfur can significantly modify also the size distribution of coarse particles during their long lifetime (Kokkola et al., 2009). With the default setup, this processing cannot be reproduced adequately. In addition, information on the sulfur mass in each size section in the coarse size range is not available in the default setup. Thus we modified the SALSA model to exclude the third subregion and broadened the second subregion to cover also the coarse-particle range, as is shown in Fig. 1 (right-hand panel). This allows a better representation of coarse particles in the stratosphere, but increases simulation time by approximately $30 \%$ due to an increased number of the particle composition tracers.

In addition to the sulfur emissions from SRM and from volcanic eruptions (described in Sect. 2.2), the MAECHAM5-HAM-SALSA simulations include aerosol emissions from anthropogenic sources and biomass burning as given in the AEROCOM database for the year 2000 (Dentener et al., 2006). For sea spray emissions, we use a pa- rameterization combining the wind-speed-dependent source functions by Monahan et al. (1986) and Smith and Harrison (1998) (Schulz et al., 2004). Dust emissions are calculated online as a function of wind speed and hydrological parameters according to the Tegen et al. (2002) scheme. We do not include volcanic ash emissions as it has been shown that ash sediments within a few days after the eruption from the stratosphere, and the area affected by the ash cloud is relatively small (Guo et al., 2004a). The effect of fine ash on the distribution of the volcanic cloud in the atmosphere is also relatively small (Niemeier et al., 2009).

The MAECHAM5-HAM-SALSA simulations were carried out with a free-running setup without nudging. Thus the dynamical feedback resulting from the additional heating from increased stratospheric sulfate load was taken into account. Global aerosol model studies of the Pinatubo eruption (Timmreck et al., 1999; Aquila et al., 2012) showed that the dynamic response to local aerosol heating has an important influence on the initial dispersal of the volcanic cloud. Performing non-interactive and interactive Pinatubo simulations, these studies revealed that an interactive coupling of the aerosol with the radiation scheme is necessary to adequately describe the observed transport characteristics over the first months after the eruption. Only the interactive model simulations where the volcanic aerosol is seen by the radiation scheme are able to simulate the observed initial southward cross-equatorial transport of the cloud as well as the aerosol lifting to higher altitudes. A further improvement of the interactive simulation is a reduced northward transport and an enhanced meridional transport towards the south, which is consistent with satellite observations. On the other hand, not running the model in the nudged mode means that the online emissions, of for example sea salt and mineral dust that are sensitive to wind speed at $10 \mathrm{~m}$ height, can differ significantly between the simulations. This can occasionally have fairly strong local effects on the aerosol radiative forcing. However, the global radiative forcing from dust is small compared to the forcing from the volcanic eruption and SRM. The radiative forcing resulting from aerosol loadings was calculated using a double call of radiation (with and without aerosols).

Because MAECHAM5-HAM-SALSA is not coupled to the ocean model, the simulations presented below have been done using fixed sea surface temperatures. All runs are preceded by a 2-year spin-up period followed by a 5-year simulation period for the baseline scenarios (defined in Sect. 2.2) and a 3-year simulation period for the sensitivity scenarios (Appendix B). Only one MAECHAM5-HAM-SALSA simulation has been performed for each of the studied scenarios to obtain the aerosol optical fields for the ESM simulations. Only for Volc we have carried out a five-member ensemble to address potential forcing uncertainties (Appendix A). 


\subsubsection{Determining climate effects with MPI-ESM}

In the second step, simulations to quantify the global and regional climate effects of concurrent SRM and volcanic eruption are performed with the Earth system model MPI-ESM (Giorgetta et al., 2013). The model is a state-of-the-art coupled 3-dimensional atmosphere-ocean-land surface model. It includes the atmospheric component ECHAM6 (Stevens et al., 2013), which is the latest version of the atmospheric model ECHAM and whose earlier version is used in the first step of this study. The atmospheric model was coupled to the Max Planck Institute Ocean Model (MPIOM) (Jungclaus et al., 2013). MPI-ESM also includes the land model JSBACH (Reick et al., 2013) and the ocean biochemistry model HAMOCC (Ilyina et al., 2013). ECHAM6 was run with the same resolution as in the first part of this study. We did not include dynamical vegetation and carbon cycle in the simulations.

In MPI-ESM, aerosol fields are prescribed. We used the same tropospheric aerosols fields based on the Kinne et al. (2013) climatology in all scenarios. In the stratosphere, we use precalculated aerosol fields from the different simulations with MAECHAM5-HAM-SALSA. The aerosol radiative properties were calculated based on monthly mean values of the aerosol effective radius and the aerosol optical depth (AOD) at $550 \mathrm{~nm}$. MPI-ESM uses a precalculated look-up table to scale AOD at $550 \mathrm{~nm}$ to the other radiation wavelengths based on the effective radius. Here MPI-ESM assumes the size distribution to consist of a single mode, which in most cases differs from the sectional size distribution in MAECHAM5-HAM-SALSA. This can lead to somewhat different radiative forcings between MAECHAM5HAM-SALSA and MPI-ESM. In our study this has been seen as overestimation of both shortwave and longwave forcing. Overestimation is slightly larger in LW-radiation and thus warming effect of MPI-ESM is overestimated in MPIESM compared to the simulations by ECHAM-HAM. Since there is very little zonal variation in the monthly mean stratospheric aerosol fields, the zonal mean aerosol fields from MAECHAM5-HAM-SALSA are used in MPI-ESM.

The atmospheric gas concentrations were fixed to year 2010 level, in accordance with the tropospheric aerosol fields and land use maps. Year 2010 concentrations were also used for methane, chlorofluorocarbon and nitrous oxide.

Experiments with a full Earth system model require a long spin-up period as the ocean component needs centuries to stabilize. We resolved this by restarting our 105-year-long spin-ups from previously run Coupled Model Intercomparison Project Phase 5 (CMIP5) simulations ending in year 2005. Since the aerosol and atmospheric gas concentrations in our simulations differed slightly from the CMIP5 runs, the 105 years of spin-up was not enough for the model to reach a full steady state; there was a small warming $\left(0.3 \mathrm{~K}\left(100 \mathrm{yr}^{-1}\right)\right.$ also after spin-up period in both CTRL and SRM simulations (see simulation details in Sect. 2.2).
This temperature change is nevertheless so small that it does not affect our conclusions.

Since the initial state of the climate system can have a significant effect on the climate impacts resulting from forcing, we ran 10-member ensembles of 5-year duration for all baseline scenarios with a volcanic eruption. To do this, we first ran the model for 50 years after the spin-up and saved the climate state after every 5 years. We then continued the simulations from each of these saved climate states for further 5 years with a volcanic eruption taking place in these specific climate conditions. The obtained results were compared to the corresponding 5-year period in the simulations without a volcanic eruption (which were run continuously for 50 years).

\subsection{Model experiments}

We simulated altogether five baseline scenarios in order to investigate the radiative and climate impacts of concurrent SRM and a volcanic eruption. To better separate the effects of SRM and the eruption, these scenarios included also simulations with only SRM or only a volcanic eruption taking place. The studied scenarios are listed in Table 1, and detailed below. Three additional sensitivity simulations investigating the sensitivity of the results to the geographical location and the seasonal timing of the eruption are presented in Appendix B.

All the simulations with SRM assumed continuous injections of $8 \mathrm{Tg}(\mathrm{S}) \mathrm{yr}^{-1}$ of $\mathrm{SO}_{2}$ between $30^{\circ} \mathrm{N}$ and $30^{\circ} \mathrm{S}$ and $20-25 \mathrm{~km}$ in the vertical. The injection strength of $8 \mathrm{Tg}(\mathrm{S}) \mathrm{yr}^{-1}$ was chosen based on previously published SRM studies and for example Niemeier et al. (2011) has shown such injection rates to lead to all-sky global shortwave radiative forcing of -3.2 to $-4.2 \mathrm{~W} \mathrm{~m}^{-2}$ in ECHAM5HAM. This forcing is roughly comparable (but opposite in sign) to forcing from doubling of $\mathrm{CO}_{2}$ from preindustrial level. Such a strong SRM forcing could be considered realistic in view of the business-as-usual scenario of the Representative Concentration Pathways (RCP8.5), which estimates that without efforts to constrain the greenhouse gas emissions the total radiative forcing from anthropogenic activities at the end of the 21 st century is roughly $8.5 \mathrm{~W} \mathrm{~m}^{-2}$ (IPCC, 2013). All the simulations with a volcanic eruption assumed an explosive eruption releasing $8.5 \mathrm{Tg}$ of sulfur to the stratosphere (Niemeier et al., 2009; Guo et al., 2004b; Read et al., 1993). This corresponds to the magnitude of the Mount Pinatubo eruption in June 1991. In all of the volcanic eruption scenarios, sulfur was injected to the height of $24 \mathrm{~km}$. The eruption was always initiated on the first day of the month at 06:00 UTC and it lasted for $3 \mathrm{~h}$.

The baseline scenarios summarized in Table 1 and detailed below were simulated first with MAECHAM5-HAMSALSA, and then with MPI-ESM using the stratospheric aerosol fields from MAECHAM5-HAM-SALSA simulations. On the other hand, the sensitivity simulations in Ap- 
Table 1. Studied sulfur injection and volcanic eruption scenarios.

\begin{tabular}{ll}
\hline Scenario & Description \\
\hline CTRL & Control simulation with no SRM or explosive eruptions \\
$\mathrm{SRM}$ & Injections of $8 \mathrm{Tg}(\mathrm{S}) \mathrm{yr}^{-1}$ of $\mathrm{SO}_{2}$ between latitudes $30^{\circ} \mathrm{N}$ and $30^{\circ} \mathrm{S}$ between \\
& 20 and $25 \mathrm{~km}$ altitude \\
Volc & Volcanic eruption at the site of Mount Pinatubo $\left(15.14^{\circ} \mathrm{N}, 120.35^{\circ} \mathrm{E}\right)$ on $1 \mathrm{July}$. \\
& $8.5 \mathrm{Tg}$ of sulfur $\left(\right.$ as $\left.\mathrm{SO}_{2}\right)$ injected at $24 \mathrm{~km}$ \\
SRM Volc & Volcanic eruption during SRM. SRM suspended immediately after the eruption \\
SRM Cont & Volcanic eruption during SRM. SRM still continued after the eruption
\end{tabular}

pendix B were run only with MAECHAM5-HAM-SALSA because of the computational expense of the MPI-ESM code.

The control (CTRL) simulation included only standard natural and anthropogenic aerosols with no SRM or explosive eruptions, while the simulation SRM included SRM on top of the background aerosol, but no volcanic eruption. All the baseline scenarios which simulated a volcanic eruption assumed a tropical eruption at the site of Mount Pinatubo $\left(15.14^{\circ} \mathrm{N}, 120.35^{\circ} \mathrm{E}\right)$, where a real explosive eruption took place in summer 1991 . We simulated a July eruption at this site both in background conditions (simulation Volc) and during SRM (simulation SRM Volc and SRM Cont). Due to safety and economic considerations, it might be that SRM is suspended at some point after the eruption. When this would happen depends on several factors (decision-making process, magnitude/timing of volcano). Here we study cases where SRM was suspended immediately after the eruption (SRM Volc) and we also simulated a scenario where SRM was continued despite the eruption (SRM Cont). The purpose of the latter simulation was also to study how additive the radiative effects of volcanic eruption and solar radiation management are. It should be noted that if the SRM injections are suspended after a volcanic eruption, the injections should be restarted after some time from the eruption to prevent abrupt warming. However, we do not simulate the restart of SRM injections in this study.

\section{Results}

\subsection{Microphysical simulations of volcanic eruption and SRM compared to the measurements and previous studies}

A comparison of the Volc simulation against observations of the Pinatubo 1991 eruption shows that the model reproduces well the temporal behaviour of particle effective radius after a tropical eruption (Fig. A1b in Appendix A). The model overestimates sulfate burden compared to those retrieved from the HIRS satellite observations (Baran and Foot, 1994) during the first 12 months after the eruption (Fig. A1 in Appendix A). There are several previous global model studies that where evolution of stratospheric aerosols following Pinatubo eruption has been investigated. Many of these shows similar sulfate burden than in the our study and overestimation of sulfate burden compared to the HIRS data (Niemeier et al., 2009; English et al., 2012; Dhomse et al., 2014; Sheng et al., 2015). This comparison between the limited set of the observational data and with other modelling studies gives us confidence that the new MAECHAM5HAM-SALSA set-up simulates aerosol loads and properties consistent to observations under high stratospheric sulfur conditions.

We first looked at the aerosol burdens and the radiative impacts of a tropical volcanic eruption and SRM separately based on the MAECHAM5-HAM-SALSA runs (simulations Volc and SRM, respectively). The maximum stratospheric sulfate burden after the volcanic eruption (Volc) is $8.31 \mathrm{Tg}(\mathrm{S}) .75 \%$ of the erupted $\mathrm{SO}_{2}$ is oxidized during 2 months after the eruption and the global maximum of sulfate burden is reached 5 months after the eruption (Fig. 2a, black solid line). After this, the burden starts to decline rapidly, but remains above the level that was simulated prior to the eruption for approximately 4 years. On the other hand, continuous geoengineering with $8 \mathrm{Tg}(\mathrm{S}) \mathrm{yr}^{-1}$ (SRM) leads to the global stratospheric sulfate burden of $7.8 \mathrm{Tg}(\mathrm{S})$ with only little variation in time (Fig. 2a, dashed black line). The total sulfur amount $\left(\mathrm{SO}_{2}\right.$ and sulfate) in the stratosphere is 8.8 $\mathrm{Tg}(\mathrm{S})$ which indicates the average sulfur lifetime (sulfur burden divided by the amount of the injected sulfur) in the stratosphere to be 1.1 years. As previous studies have shown, the lifetime of sulfur is strongly dependent on the injection area and height, and the amount of injected sulfur. Some of the studies have shown a lifetime of clearly less than a year for the comparable magnitude of injected sulfur, when sulfur is injected at a lower height than in our study (Heckendorn et al., 2009; Pierce et al., 2010; Niemeier et al., 2011; English et al., 2012), slightly under a year when sulfur is injected at the same height as here (Heckendorn et al., 2009; Pierce et al., 2010), and over a year when sulfur is injected higher (Niemeier et al., 2011). Thus, overall our results are in good agreement with the previous studies.

The maximum clear-sky shortwave (SW) surface forcing in the Volc simulation reaches $-6.36 \mathrm{~W} \mathrm{~m}^{-2}$ (Fig. 2b), which is close to the average global mean forcing of $-6.00 \mathrm{~W} \mathrm{~m}^{-2}$ 

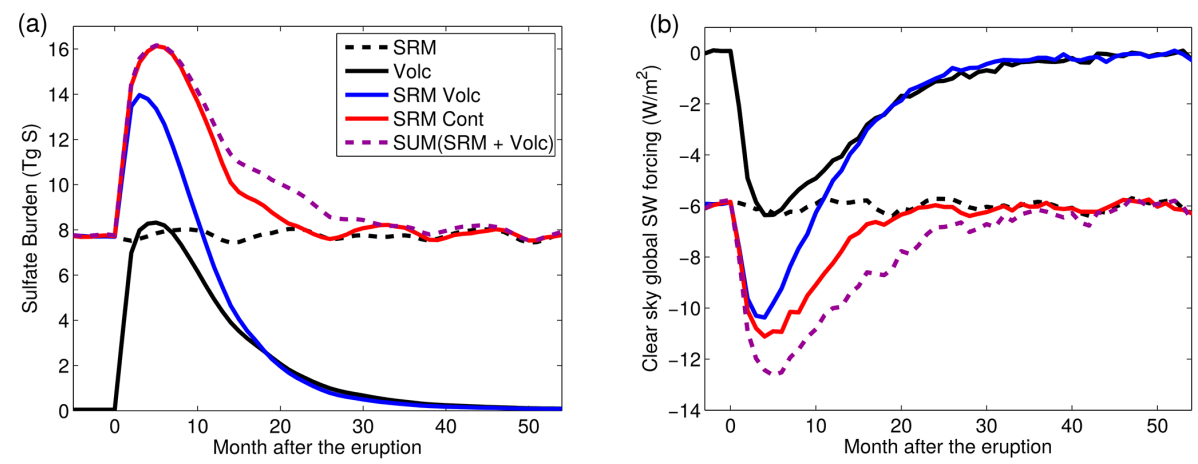

Figure 2. (a) Stratospheric sulfate burden and (b) global mean clear-sky shortwave radiative forcing at the surface in the different scenarios. In addition, the dashed purple line represents the sum of SRM and Volc runs, and is shown for comparison.

in the SRM simulation, as could be expected based on the similar maximum and steady-state sulfate burdens, respectively (Fig. 2a). In the presence of clouds, the change in SW all-sky flux in SRM is smaller $\left(-3.38 \mathrm{~W} \mathrm{~m}^{-2}\right)$ than in clear-sky conditions. Radiative forcing from the SRM is in agreement with previous studies where the forcing effect has been studied with climate models including an explicit aerosol microphysics description. For example, Niemeier et al. (2011) showed all-sky SW radiative forcings from -3.2 to $-4.2 \mathrm{~W} \mathrm{~m}^{-2}$ for $8 \mathrm{Tg}(\mathrm{S}) \mathrm{yr}^{-1}$ injection, and Laakso et al. (2012) a forcing of $-1.32 \mathrm{~W} \mathrm{~m}^{-2}$ for $3 \mathrm{Tg}(\mathrm{S})$ injection. On the other hand, Heckendorn et al. (2009) simulated a clearly smaller radiative forcing of $-1.68 \mathrm{~W} \mathrm{~m}^{-2}$ for $10 \mathrm{Tg}(\mathrm{S})$ injection.

The shortwave radiative effect $\left(-6.00 \mathrm{~W} \mathrm{~m}^{-2}\right)$ from the sulfate particles originating from SRM is concentrated relatively uniformly between $60^{\circ} \mathrm{N}$ and $60^{\circ} \mathrm{S}$ (not shown). SRM leads also to a $0.73 \mathrm{~W} \mathrm{~m}^{-2}$ all-sky longwave radiative forcing which is concentrated more strongly in the Tropics than in the midlatitudes and polar regions. In the case of the volcanic eruption (Volc), forcing is distributed between $30^{\circ} \mathrm{N}$ and the Equator for the first 4 months after the eruption. After that, forcing is concentrated more to the midlatitudes than the low latitudes in both hemispheres. It should be noted, however, that the initial state of the atmosphere and local winds over the eruption area at the time of the eruption can have a large impact on the distribution of sulfur released from a short-duration eruption. This can be seen for example in Fig. A2, which illustrates the hemispheric sulfur burdens from five different ensemble members of the Volc simulation (see Appendix A for details). As an example, in one of the ensemble simulations, burden is concentrated much more in the Northern Hemisphere (NH) (peak value 6.7 $\mathrm{Tg}(\mathrm{S})$ ) than in the Southern Hemisphere (SH) $(2.2 \mathrm{Tg}(\mathrm{S}))$. This leads to northern and southern hemispheric peak values of clear-sky forcings of -8.18 and $-3.72 \mathrm{~W} \mathrm{~m}^{-2}$, respectively. However, in another ensemble member sulfate is distributed more uniformly between the hemispheres $(4.8$ and $3.7 \mathrm{Tg}(\mathrm{S})$ in the $\mathrm{NH}$ and $\mathrm{SH}$, respectively) resulting in clear-sky peak forcing of $-6.04 \mathrm{~W} \mathrm{~m}^{-2}$ in the north and $-6.35 \mathrm{~W} \mathrm{~m}^{-2}$ in the south. (In the analysis above (e.g. Fig. 2), we have used simulation Volc4 from Appendix A, since it resembles most closely the 5 -member ensemble mean in terms how sulfate is distributed between the hemispheres.)

\subsection{Burden and radiative effects of concurrent volcanic eruption and SRM - results of aerosol microphysical simulations}

Next we investigated whether the radiative impacts from a volcanic eruption taking place during SRM differs from the sum of volcanic-eruption-only and SRM-only scenarios discussed in Sect. 3.1. In order to do this, we compared the SRM-only (SRM) and volcanic-eruption-only (Volc) simulations with two scenarios of concurrent eruption and SRM: SRM Volc where SRM is suspended immediately after the eruption, and SRM Cont where SRM is continued after the eruption. The magnitude, timing and location of the eruption were assumed the same as in Volc simulation.

Figure 2 shows the stratospheric sulfur burden and the global clear-sky radiative forcing from the four MAECHAM5-HAM-SALSA runs. It is evident that both the stratospheric sulfate burden and the global shortwave radiative forcing reach a maximum value and recover back to preeruption level clearly faster if the volcanic eruption happens during SRM than in stratospheric background conditions, as can be seen by comparing the scenario of volcanic eruption concurrent with SRM (solid blue and red lines) to the sum of eruption-only and SRM-only scenarios (dashed purple line). This is the case especially when SRM is suspended immediately after the eruption (simulation SRM Volc). In this case, in our simulation set-up, it takes only 10 months for the stratospheric sulfate burden and the global radiative effect to recover to the state before the volcanic eruption. On the other hand, if the eruption happens in stratospheric background conditions (Volc), it takes approximately 40 months before the sulfate burden and the radiative effect return to their pre-eruption values. In addition, the global SW radia- 
tive forcing reaches a maximum value two months earlier in SRM Volc than in Volc (Fig. 2b). In comparison to the level before the eruption, the peak increase in radiative forcing is $32 \%$ smaller in SRM Volc $\left(-4.30 \mathrm{~W} \mathrm{~m}^{-2}\right)$ than in Volc $\left(-6.36 \mathrm{~W} \mathrm{~m}^{-2}\right)$.

The first, somewhat trivial reason for lower and shorterlasting radiative forcing in SRM Volc is that because SRM is suspended immediately after the eruption, the stratospheric sulfur load will recover from both the volcanic eruption and SRM. If the stratospheric background sulfur level is not upheld by continuous sulfur injections as before the eruption, the sulfur burden will return back to the pre-eruption conditions within less than a year after the eruption. However, the different responses to a volcanic eruption during background (Volc) and SRM (SRM Volc) conditions cannot be explained only by suspended SRM injections. This can be seen in Fig. 2a in scenario SRM Cont (solid red line) where geoengineering is continued after the volcanic eruption: also in this case the lifetime of sulfate particles is shorter than in Volc. There is a similar increase in the sulfate burden in the first 10 months after the eruption in the Volc and SRM Cont scenarios as is seen by comparing the red and purple lines in Fig. 2; here the purple dashed line shows the calculated sum of the effects from separate simulations of Volc and SRM. This scales the Volc simulation to the same start level as SRM Cont. After the first 10 months the sulfate burden starts to decrease faster in the SRM Cont scenario and is back to the level prior to the eruption after 20 months from the eruption, compared with $\sim 40$ months in the Volc run. The difference between the two scenarios can be seen even more clearly in the shortwave radiative forcing (Fig. 2b). When the volcano erupts during SRM, the contribution of the eruption to the forcing is lower immediately after the eruption than after the eruption in Volc and the peak increase in global mean radiative forcing compared the pre-eruption level is $21 \%$ lower in SRM Cont $\left(-5.04 \mathrm{~W} \mathrm{~m}^{-2}\right)$ than in Volc $\left(-6.36 \mathrm{~W} \mathrm{~m}^{-2}\right)$.

The reason for these findings is that the initial stratospheric aerosol load is significantly different when the volcanic eruption occurs during stratospheric sulfur geoengineering than under background conditions. If a volcano erupts concurrently with SRM, sulfur from the eruption does not only form new particles but also condenses onto pre-existing particles. Furthermore, the new small particles that are formed after the eruption coagulate effectively with the existing larger particles from the SRM injections. This means that a situation develops where there are fewer but larger particles compared to a case without SRM. The increased particle size can also be seen in Fig. 3 which shows the effective radius in the SRM injection area. These larger particles in SRM Volc and SRM Cont have higher gravitation settling velocities and sediment faster. Thus, about 30 months after the eruption the effective radius in SRM Volc becomes even smaller than in simulation Volc, when larger particles have sedimented out of the atmosphere in SRM Volc. Figure 2 indicates the impact on the radiative forcing. SW scattering gets less effective with

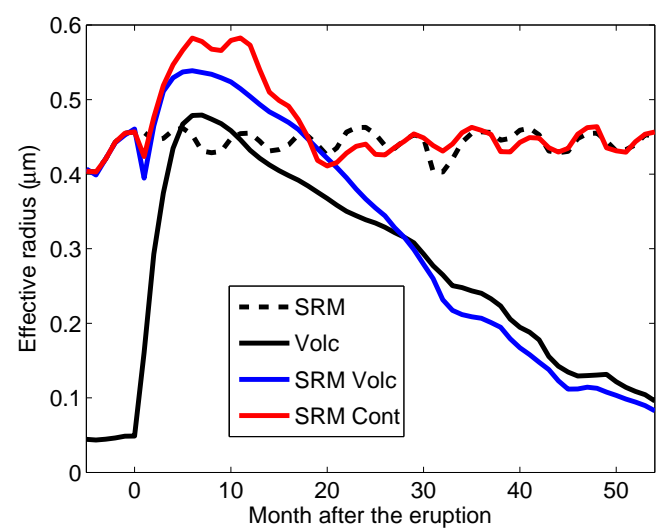

Figure 3. Mean effective radius in the different scenarios between $20^{\circ} \mathrm{N}$ and $20^{\circ} \mathrm{S}$ latitudes and between 20 and $25 \mathrm{~km}$ altitude levels.

increasing particle size (Pierce et al., 2010) and, although the stratospheric sulfur burden is the same in the first months after the eruption in SRM Cont and in the sum of Volc and SRM, there is a clear difference in the radiative forcing. This indicates that the number-to-mass ratio of particles is smaller in SRM Cont than in the calculated sum from Volc and SRM.

Additional sensitivity simulations with MAECHAM5SALSA discussed in more detail in Appendix B show that the season when the tropical eruption occurs defines how sulfate from the eruption is distributed between the hemispheres. An eruption in January leads to a larger sulfur burden in the Northern Hemisphere than an eruption in July (Toohey et al., 2011; Aquila et al., 2012). This conclusion holds also if the eruption occurs during geoengineering, at least in cases where SRM is implemented evenly to both hemispheres. In the case of an eruption outside the Tropics, the season of the eruption can have a large impact on the magnitudes of both the sulfate burden and the global radiative forcing. Therefore it very likely has an impact also on the regional climates, which further defines when and where suspended stratospheric sulfur injections should be restarted. However, due to the computational expense of the fully coupled MPI-ESM, we limit our analysis of the climate impacts below only to the baseline scenarios. It should be noted that the impact after concurrent volcanic eruption and SRM may depend also on the altitude at which sulfur is released. Increasing the injection height increases the lifetime of sulfate (Niemeier and Timmreck, 2015). If sulfur from the eruption is released at the same altitude where SRM sulfur resides, it might lead to locally larger sulfur concentration and therefore to larger particles compared to a case when sulfur from the eruption is released below the SRM sulfate layer. Dependent on the geographical location this volcanic sulfur can still reach the SRM layer, e.g in the case of tropical eruption with the ascending branch of the Brewer-Dobson circulation. However, this happens on much longer timescales. 

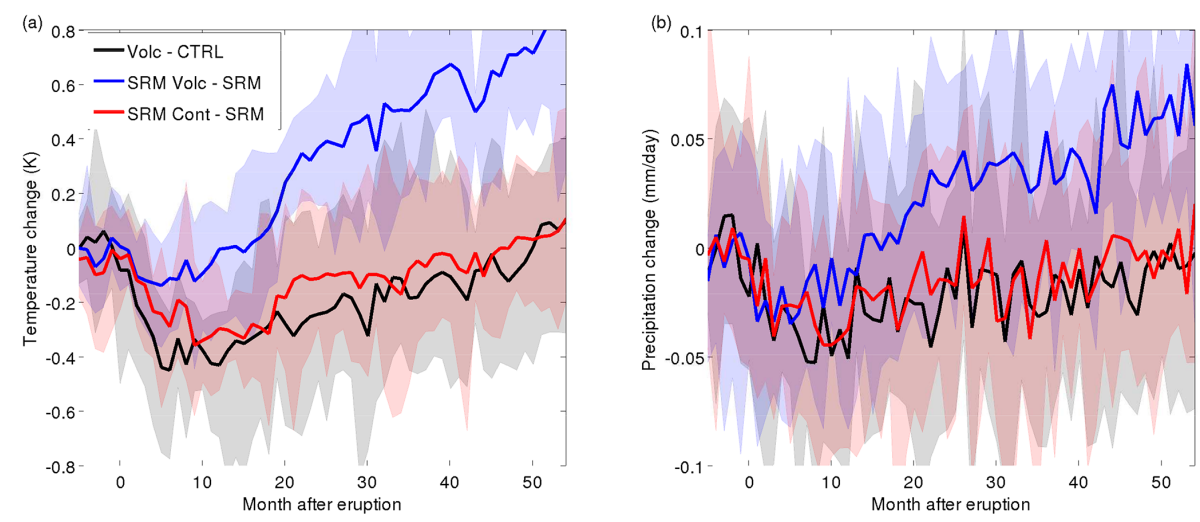

Figure 4. Global mean $2 \mathrm{~m}$ (a) temperature and (b) precipitation changes after the volcanic eruption compared to the background condition (black line) and during solar radiation management (blue and red lines). Solid lines are mean values of the ten members of the ensemble simulations. The maximum and minimum values of the ensemble are depicted by shaded areas.

\subsection{Climate effects from concurrent volcanic eruption and SRM - results of ESM simulations}

In this section we investigate how the radiative forcings simulated for the different scenarios in section 3.2 translate into global and regional climate impacts. For this purpose, we implemented the simulated AOD and effective radius of stratospheric sulfate aerosol from MAECHAM5-HAM-SALSA to MPI-ESM, similar to Timmreck et al. (2010).

Figure 4 a shows the global mean temperature change compared to the pre-eruption climate. Simulation Volc (black line) leads to cooling with an ensemble mean peak value of $-0.45 \mathrm{~K}$ reached 6 months after the eruption. On average, this cooling impact declines clearly more slowly than the radiative forcing after the eruption (shown in Fig. 2b): 1 year after the eruption the radiative forcing was $64 \%$ of its peak value, and subsequently 17 and $8 \%$ of the peak value 2 and 3 years after the eruption. On the other hand, the ensemble mean temperature change 1 year after the eruption is $84 \%$ of the peak value. Subsequently, 2 and 3 years after the eruption the temperature change is still 53 and $30 \%$ of the peak value. It should be noted, however, that the variation in temperature change is quite large between the 10 climate simulation ensemble members $( \pm 0.67 \mathrm{~K}$ compared the mean of the ensemble). In fact, in some of the ensemble members the pre-eruption temperature is reached already approximately 15 months after the eruption.

Figure $4 \mathrm{a}$ also shows that on average a volcanic eruption during continued SRM (simulation SRM Cont, red line) leads to on average $33 \%$ smaller cooling for the next 3 years after the eruption than under unperturbed atmospheric conditions. If SRM is suspended (SRM Volc), the maximum value of the global cooling is only about one-third (i.e. less than $0.14 \mathrm{~K}$ at maximum for the ensemble mean) compared to an eruption to the non-geoengineered background stratosphere (simulation Volc). This is consistent with the clearly smaller radiative forcings predicted for the eruption during SRM than in the background atmospheric conditions (Fig. 2b). Similar to Volc simulation, the global mean temperature is lower compared to the pre-eruption level and even radiative forcing has levelled off. In SRM Volc scenario the global mean shortwave radiative forcing from the sulfate particles has reached the pre-eruption level after 10 months from the eruption but there would be still some global cooling after 12 months from the eruption. Our simulations indicate that if SRM is suspended but not restarted, there is fast warming compared to the pre-eruption temperature within the first 20 months after the eruption.

Figure 5 depicts the regional surface temperature changes simulated in the different scenarios. Geoengineering alone (SRM) would lead to global ensemble mean cooling of $-1.35 \mathrm{~K}$ compared to the CTRL case. As Fig. 5a shows, cooling is clearly stronger in the Northern Hemisphere $(-1.65 \mathrm{~K})$ than in the Southern Hemisphere $(-1.05 \mathrm{~K})$. The strongest regional cooling is seen in the northern high latitudes (regional average of $-2.2 \mathrm{~K}$ north of $50^{\circ} \mathrm{N}$ ). The smallest cooling effect, or even slight warming, is predicted over the southern oceans. These general features are consistent with the GeoMIP multimodel intercomparison when only the impact of SRM (and not of combined SRM and $\mathrm{CO}_{2}$ increase) is considered: Kravitz et al. (2013a) show a very similar decrease in polar temperature when subtracting temperature change under increased $\mathrm{CO}_{2}$ from the combined SRM and $\mathrm{CO}_{2}$ increase results.

For the three volcanic eruption scenarios we concentrate on the regional climate impacts during the first year after the eruption. Figure $5 \mathrm{~b}$ shows the 1-year-mean temperature anomaly at the surface after a volcanic eruption into the unperturbed background stratosphere in simulation Volc. As expected, the cooling impact from the volcanic event over the first year following the eruption is clearly smaller than that from continuously deployed SRM. While there are some similar features in the temperature change patterns between Fig. 5a and b (such as more cooling in the Northern than in 

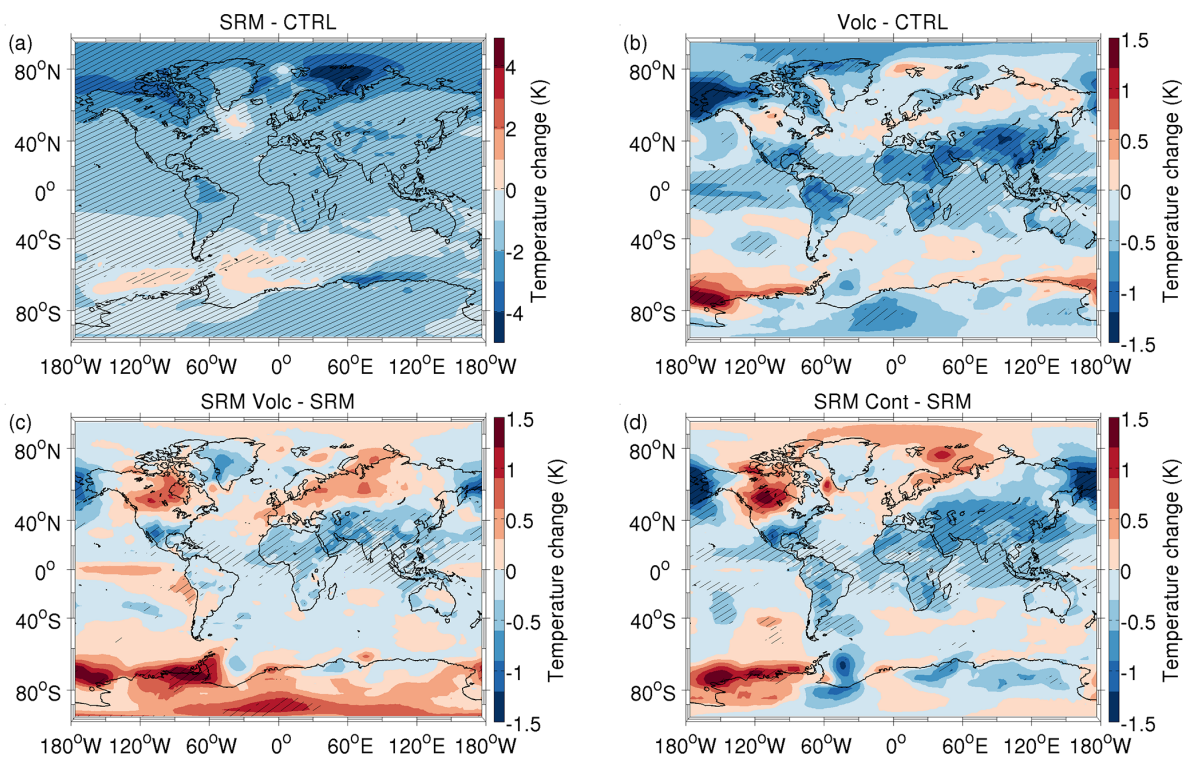

Figure 5. Ensemble mean change in annual mean $2 \mathrm{~m}$ temperature. (a) 50-year mean temperature change in SRM scenario; 1-year-mean temperature change after the volcanic eruption in (b) Volc, (c) SRM Volc and (d) SRM Cont compared to the pre-eruption climate (CTRL for SRM and Volc, and SRM for SRM Volc and SRM Cont). Hatching indicates a regions where the change of temperature is statistically significant at $95 \%$ level. Significance level was estimated using Student's unpaired $t$ test with a sample of 10 ensemble member means for panels (b-d) and a sample of 50 annual means for panel (a). Note the different scale in panel (a).

the Southern Hemisphere, and warming in the southern Pacific), clear differences also emerge, especially in $\mathrm{NH}$ midand high latitudes where there is less cooling, and in some regions even warming, after the eruption. During the first year after the eruption, sulfate from the tropical eruption is mainly concentrated at low latitudes where there is also strong solar intensity and thus strong radiative effect from the enhanced stratospheric aerosol layer. During the subsequent years, sulfate transport towards the poles causes stronger cooling also in the high latitudes. The global yearly mean temperature change is $-0.34 \mathrm{~K}$ for the first year after the eruption, then decreasing to a value of -0.30 for the second year from the eruption. However, there is an increased temperature response north of $50^{\circ} \mathrm{N}$ from the first year mean of $-0.30 \mathrm{~K}$ to the second year mean of $-0.44 \mathrm{~K}$. Even though there is larger cooling at the midlatitudes in the second year after the eruption, we see $0.06 \mathrm{~K}$ warming north of $75^{\circ} \mathrm{N}$ in the second boreal winter (December-February) after the eruption. Winter warming after a volcanic eruption has been seen also in observations (e.g. Robock and Mao, 1992; Fischer et al., 2007), though the current generation of CMIP5 models has problems to reproduce the $\mathrm{NH}$ post-volcanic winter warming pattern (Driscoll et al., 2012).

When the eruption takes place during geoengineering and SRM injections are suspended (SRM Volc), the global 1-year ensemble mean temperature change is only $-0.09 \mathrm{~K}$ during the first year after the eruption (Fig. 5c). This small global impact is due to the fact that the anomaly in SW radiation after the volcanic eruption is relatively small in magnitude and only about 10 months in duration when geoengineering is suspended after the eruption (Fig. 2b). However, the regional impacts are much stronger and show distinctly different patterns from those in Volc (Fig. 5b). Volc scenario leads to $0.30 \mathrm{~K}$ cooling north from $50^{\circ} \mathrm{N}$ in the ensemble mean, while there is small warming of $0.02 \mathrm{~K}$ in SRM Volc after the first year from eruption. The warming is concentrated over the central areas of Canada, where the ensemble mean temperature increase is more than $1 \mathrm{~K}$, and over North Eurasia, where the temperature increase is more than $0.5 \mathrm{~K}$. It should be noted, however, that in most parts of these regions the warming signal is not statistically significant.

There are also differences in the southern hemispheric temperatures between the different scenarios. While Volc scenario leads to small $-0.02 \mathrm{~K}$ mean cooling south of $50^{\circ} \mathrm{S}$ in the first year after the eruption, there is a warming of $0.14 \mathrm{~K}$ in the SRM Volc scenario. In addition, over the Pacific equatorial area the Volc scenario leads to a cooling of more than $-0.5 \mathrm{~K}$ while SRM Volc scenario leads to a warming of more than $0.5 \mathrm{~K}$. These differences between Volc and SRM Volc simulations imply that previous observations of regional climate impacts after an explosive eruption, such as Pinatubo in 1991, may not offer a reliable analogue for the impacts after an eruption during SRM. It is important to note, however, that just like there were some variations in the global mean temperature between individual ensemble members, there are also variations in regional changes between the members. Variations are the largest over high latitudes, while most of the individual ensemble members are in good 
agreement at the low latitudes (hatching in Fig. 5), where the change in temperature is the largest.

The main reason for the differences between Volc and SRM Volc is that in the latter simulation the volcanic eruption is preceded by SRM injections (providing a baseline stratospheric sulfate load) which are suspended immediately after the eruption. Thus, after the eruption the baseline sulfate load starts decreasing, especially far away from the eruption site, and, therefore, during the first year after the eruption there are regions with a positive radiative forcing compared to the pre-eruption level.

We also find that there could be regional warming in some regions after the volcanic eruption even if the SRM injections were still continued (Fig. 5d, SRM Cont). This warming is concentrated in the high latitudes and areas with relatively little solar shortwave radiation but with large stratospheric particles capable of absorbing outgoing longwave radiation. The warming is strongest in the first post-eruption boreal winter when some areas over Canada, Northeast Europe and western Russia experience over $0.5 \mathrm{~K}$ warming (not shown). Such significant regional warming means that the ensemble mean temperature change north of $50^{\circ} \mathrm{N}$ during the first post-eruption winter is only $-0.05 \mathrm{~K}$. In some parts of the Southern Ocean a volcanic eruption could enhance the warming signal caused already by SRM (Fig. 5a).

It is also worth noting that the stratospheric sulfur geoengineering with $8 \mathrm{Tg}(\mathrm{S}) \mathrm{yr}^{-1}$ itself leads only to $-1.35 \mathrm{~K}$ global temperature change in our simulations. Such weak response is likely at least partly due to the radiation calculations in MPI-ESM, which assume a single modal particle size distribution (see Sect. 2.1.2 for details). Compared to a more flat size distribution simulated by the sectional approach of MAECHAM5-HAM-SALSA, this assumption leads to an overestimation longwave (LW) AOD which is calculated from $550 \mathrm{~nm}$ AOD. This in turn leads to an overestimation of the longwave radiative forcing $\left(0.7 \mathrm{~W} \mathrm{~m}^{-2}\right.$ for SRM) while the shortwave forcing is less affected $\left(-0.2 \mathrm{~W} \mathrm{~m}^{-2}\right.$ for SRM). However, this does not affect the conclusions of this study.

In addition to the changes in surface temperature, volcanic eruptions will also lead to changes in precipitation. Figure $4 \mathrm{~b}$ shows the global mean precipitation change after a volcanic eruption in the three scenarios. There is a similar decrease in the precipitation in all volcanic scenarios during the first 5 months after the eruption. Thereafter there is a similar slow increase in the global mean precipitation in the simulations Volc and SRM Cont but a clearly faster increase in SRM Volc. This faster increase would also, about 1 year after the eruption, lead to a higher global ensemble mean precipitation compared to the pre-eruption climate.

The global 1-year mean precipitation change is 0.036 , 0.023 and $0.031 \mathrm{~mm} \mathrm{day}^{-1}$ for Volc, SRM Volc and SRM Cont respectively for the first year after the eruption. Earlier studies (Bala et al., 2008; Kravitz et al., 2013a, b; Niemeier et al., 2013) have already shown that geoengineering leads to a reduction in the global precipitation compared to the climate without geoengineering. In our SRM simulation, we obtain a precipitation reduction of $0.11 \mathrm{~mm} \mathrm{day}^{-1}(2.8 \%)$, which is clearly larger than the impact after the volcanic eruption.

The stratospheric sulfate affects precipitation via two climate system responses. The first one is the rapid adjustment (fast response) due to atmospheric forcing, such as change in solar irradiance, on a short timescale. The second one is the feedback response (slow response) due to temperature changes (Bony et al., 2013; Ferraro et al., 2014; Fuglestvedt et al., 2014; Kravitz et al., 2013b). The signals from both of these responses can be seen in Fig. 4b, especially in the simulation SRM Volc (blue line). During the first months after the eruption, the precipitation drops relatively rapidly which corresponds well with the rapid change in the radiative forcing (Fig. 2b); at the same time, the temperature change in SRM Volc is less steep (Fig. 4a). This implies that in the first months following the eruption, the precipitation change is more affected by the change in the radiation than the change in the temperature. On the other hand, after 2 years from the eruption there is only small $\mathrm{SW}$ radiative effect left from the eruption (and the SRM prior to eruption) but there is still a decrease in the global mean precipitation. During this period, precipitation is predominantly affected by the change in temperature.

Figure 6 shows the regional precipitation changes in each of the studied scenarios. The largest changes after geoengineering (SRM) are seen in the tropical convective region where SRM reduces the precipitation rate in large areas by as much as $0.5 \mathrm{~mm} \mathrm{day}^{-1}$ (Fig. 6a). This is in good agreement with previous multi-model studies (Kravitz et al., 2013a). In our simulations, an increase of the same magnitude in the precipitation rate is predicted just north of Australia, which has not been seen in previous model intercomparisons (Kravitz et al., 2013a).

Although the precipitation patterns in SRM and Volc are similar in low latitudes, differences are seen especially in NH mid- and high latitudes where SRM shows clearly larger reduction in precipitation. The zonal mean value is $-0.15 \mathrm{~mm} \mathrm{day}^{-1}$ in both $50^{\circ}$ north and south latitudes. In these areas, there is clearly less evaporation in the SRM scenario which is not seen in the first year after the volcanic eruption (Volc) and which would lead to different precipitation patterns. Similar to the temperature change, our simulations indicate that a tropical volcanic eruption impacts precipitation patterns differently in unperturbed and SRM conditions. In fact, a volcanic eruption during geoengineering (SRM Volc and SRM Cont) leads to an opposite precipitation change pattern than an eruption to the unperturbed atmosphere (Volc) over the tropical area in the Pacific and Atlantic (Fig. 6c and d). In these areas, a volcanic eruption during SRM leads to the increase in the evaporation flux at the surface during the first year after the eruption, whereas the evaporation flux decreases if the eruption takes place in unperturbed conditions. This is caused by different tropical tem- 

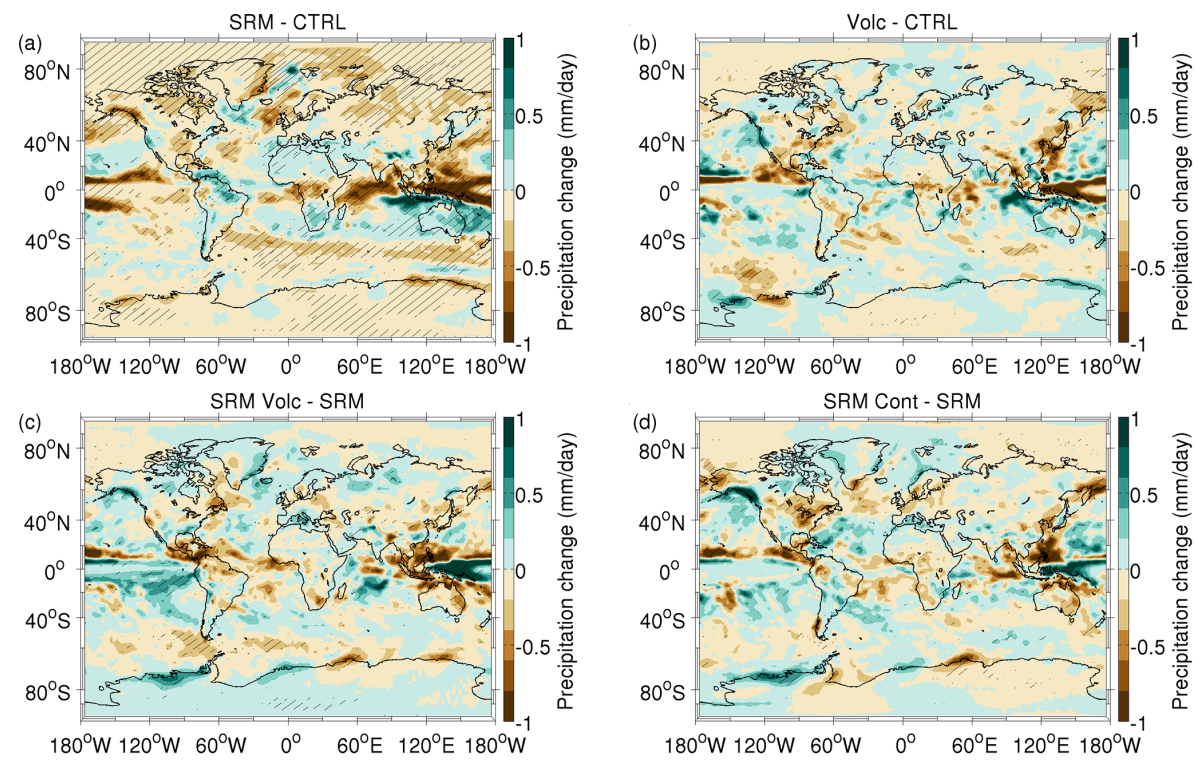

Figure 6. Ensemble-mean precipitation change in (a) 50-year mean precipitation change in the SRM scenario. The change in 1 year mean precipitation after the volcanic eruption in (b) Volc, (c) SRM Volc and (d) SRM Cont compared to the pre-eruption climate (CTRL for SRM and Volc, and SRM for SRM Volc and SRM Cont). Panels (b-d) show the 1-year-mean temperature after the eruption. Panel (a) shows the mean over the corresponding 1-year-periods as the other panels. Hatching indicates a regions where the change of precipitation is statistically significant at $95 \%$ level. Significance level was estimated using Student's unpaired $t$ test with a sample of 10 ensemble member means for panels (b-d) and a sample of 50 annual means for panel (a).

perature responses between the simulations (Fig. 5). Compared to the pre-eruption values, in simulations SRM and Volc, equatorial sea surface temperature (SST) anomalies (latitudes $0-10^{\circ} \mathrm{N}$ ) are relatively colder than the SST anomalies over latitudes $10-20^{\circ} \mathrm{N}$. In simulation SRM, the difference in SST anomaly between these areas is $-0.02 \mathrm{~K}$ and in simulation Volc it is $-0.05 \mathrm{~K}$. On the other hand, in simulations SRM Volc and SRM Cont, equatorial SST anomalies are relatively warmer than those over latitudes $10-20^{\circ} \mathrm{N}$. In SRM Volc, the difference in temperature anomaly is $0.13 \mathrm{~K}$ and in SRM Cont it is $0.05 \mathrm{~K}$. However, these changes in precipitation are not significant and a larger ensemble would be necessary for further detailed investigations. It should also be noted that here we have studied an unrealistic scenario where SRM is implemented without global warming. If warming from increased greenhouse gases had been included in the scenarios, the temperature gradient could be very different in simulation SRM which could lead to different precipitation patterns. There is also a large natural variability in the precipitation rates and as the precipitation changes after the eruption are relatively small, our results are statistically significant only in a relatively small area (hatching in Fig. 6).

\section{Summary and conclusions}

We have used an aerosol microphysical model coupled to an atmosphere-only GCM as well as an ESM to estimate the combined effects of stratospheric sulfur geoengineering and a large volcanic eruption. First, MAECHAM5-HAMSALSA was used to define the stratospheric aerosol fields and optical properties in several volcanic eruption and SRM scenarios. Following the approach introduced in Timmreck et al. (2010) and Niemeier et al. (2013), these parameters were then applied in the Max Planck Institute Earth System Model (MPI-ESM) in order to study their effects on the temperature and precipitation.

According to our simulations, climate responses to be expected after a volcanic eruption during SRM depend strongly on whether SRM is continued or halted after the eruption. In the former case, the peak additional forcing is about $21 \%$ lower and the global cooling $33 \%$ smaller than compared to an eruption taking place in non-SRM world. However, the peak additional burden and changes in global mean precipitation are fairly similar regardless of whether the eruption takes place in a SRM or non-SRM world. On the other hand, if SRM is stopped immediately after the eruption, the peak burden is $24 \%$ and forcing $32 \%$ lower and reached earlier compared to the case with unperturbed atmosphere. Furthermore, the forcing from the eruption declines significantly faster, implying that if SRM was stopped after the eruption, it would need to be restarted relatively soon (in our scenario within 10 months) after the eruption to maintain the pre-eruption forcing level.

In line with the burden and forcing results, the simulated global and regional climate impacts were also distinctly different depending on whether the volcano erupts during SRM 
or in the background stratospheric conditions. In the investigated scenarios, a Pinatubo-type eruption during SRM caused a maximum global ensemble-mean cooling of only $0.14 \mathrm{~K}$ (assuming that SRM is paused after the eruption) compared to $0.45 \mathrm{~K}$ in the background case. On the other hand, the ensemble-mean decline in the precipitation rate was $36 \%$ lower for the first year after the eruption during SRM than for the eruption under unperturbed atmospheric conditions. Both the global mean temperature and the precipitation rate recovered to the pre-eruption level in about 1 year, compared to approximately 40 months in the background case. If SRM was continued despite the large volcanic eruption, the global ensemble mean cooling was averagely $-0.19 \mathrm{~K}(-(0.31-0.02) \mathrm{K}$ in individual ensemble member) for 3 subsequent years after the eruption. This is only $67 \%$ of 3 subsequent years cooling after the eruption in normal unperturbed atmospheric conditions, when global ensemble mean cooling was $-0.28 \mathrm{~K}(-(0.49-0.15) \mathrm{K})$.

In terms of the regional climate impacts, we found cooling throughout most of the Tropics regardless of whether the eruption took place during SRM or in the background conditions, but a clear warming signal (up to $1^{\circ} \mathrm{C}$ ) in large parts of the mid- and high latitudes in the former scenario. While it should be noted that the regional temperature changes were statistically significant mostly only in the Tropics, the declining stratospheric aerosol load compared to the pre-eruption level (as a result of switching off SRM after the eruption) offers a plausible physical mechanism for the simulated warming signal in the mid- and high latitudes. On the other hand, the largest regional precipitation responses were seen in the Tropics. Interestingly, the sign of the precipitation change was opposite in SRM Volc and SRM Cont than in the Volc and SRM in large parts of the tropical Pacific. We attribute this difference to a clearly weaker tropical cooling, or in some areas even a slight warming, in the former scenario leading to an increased evaporation in the first year following the eruption.

Based on both the simulated global and regional responses, we conclude that previous observations of explosive volcanic eruptions in stratospheric background conditions, such as the Mount Pinatubo eruption in 1991, are likely not directly applicable to estimating the radiative and climate impacts of an eruption during stratospheric geoengineering. The global mean temperature and precipitation decline from the eruption can be significantly alleviated if the SRM is switched off after the eruption; however, large regional impacts could still be expected during the first year following the eruption. 


\section{Appendix A: Evaluation of the model: Pinatubo eruption 1991, comparison between model and measurements}

This is the first study where ECHAM5-HAM-SALSA has been used to simulate aerosol processes in the stratosphere. To ensure that the model can be applied for simulation of high aerosol load in the stratosphere, we evaluated the model's ability to reproduce the response of the stratospheric aerosol layer to the Mount Pinatubo eruption in 1991. We simulated the Pinatubo eruption with MAECHAM5-HAMSALSA making a five-member ensemble initiated on 1 July (see simulation Volc in Sect. 2.2 for details). In these simulations, we first used the same 2-year spin-up for all ensemble members. After the spin-up, the model was slightly perturbed by a very small change in a model tuning parameter and then run freely for 6 months, in order to create different atmospheric states for the volcano to erupt into. Only after this was the volcanic eruption triggered in the model. Simulated sulfur burdens and particle effective radii were compared against observations from satellite (HIRS) (Baran and Foot, 1994) and lidar measurements (Ansmann et al., 1997), respectively.

Figure A1 shows that the model results are in general in good agreement with the observations. For example, the model correctly indicates that the oxidation of $\mathrm{SO}_{2}$ and formation of sulfate particles is very fast right after the eruption. However, the simulated sulfate burden peaks at higher values than the observations after which sulfur burden decreases below observed values approximately 1 year after the eruption. This has been seen also in previous studies (e.g. English et al., 2013, and Niemeier et al., 2009). English et al. (2013) suggest that this might be because aerosol heating was not included their model. Our model includes the aerosol heating effect and still underestimates the burden. This might be due to poleward transport at the stratosphere which is overestimated in the model (Niemeier et al., 2009).

In all of the ensemble members the effective radius is generally overestimated during months 3-8 after the eruption, although there is also large variation in the measured values (Fig. A1b). The simulated maximum value for the effective radius is reached 3-4 months earlier than in observations.
After 8 months from the eruption results from all the model simulations are in good agreement with observations.

One possible explanation for the larger burden and effective radius in the model could be that the amount of erupted sulfur is overestimated in the model compared to the real Pinatubo eruption. Recent global stratospheric aerosol studies indicate a much better agreement with observations if they assume a smaller amount of the volcanic $\mathrm{SO}_{2}$ emission of 5 to $7 \mathrm{Tg}$ (S) (Dhomse et al., 2014; Sheng et al., 2015). Another possible explanation is that a larger proportion of sulfur was removed from the stratosphere during the first months after the eruption due the cross-tropopause transport out of the stratosphere or the enhanced removal with ash and ice cloud (Dhomse et al., 2014). Unfortunately, there is only a limited amount of observations after the eruption of Pinatubo which makes comparison between model results and observations difficult. However, our results here are similar to the previous model studies (Niemeier et al., 2009; English et al., 2012; Dhomse et al., 2014; Sheng et al., 2015).

There is some variation in the predicted peak burden and effective radii between the five members of the ensemble simulation (Fig. A1). This indicates that the results are dependent on the local stratospheric conditions at the time of the eruption. Depending on meridional wind patterns during and after the eruption, the released sulfur can be distributed in very different ways between the hemispheres. This can be seen in Fig. A2 which shows the sulfate burdens after the eruption separately in the northern and southern hemispheres. As the figure shows, in simulation Volc1 over $70 \%$ of the sulfate from the eruption is distributed to the Northern Hemisphere, whereas in Volc5 simulation it is distributed quite evenly to both hemispheres. These very different spatial distributions of sulfate lead to the aerosol optical depth (AOD) fields illustrated in Fig. A3. The AOD in the Northern Hemisphere is clearly higher in the Volc1 simulation (panel a) than in the Volc5 simulation (panel b) for about 18 months after the eruption, whereas the opposite is true for the Southern Hemisphere for approximately the first 2 years following the eruption. These results highlight that when investigating the climate effects of a volcanic eruption during SRM, an ensemble approach is necessary. 

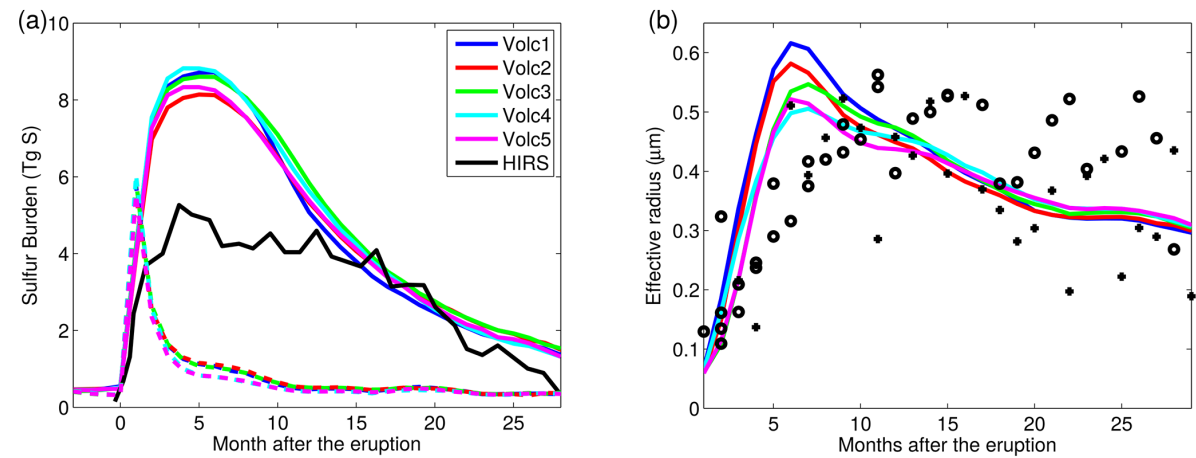

Figure A1. (a) Global $\mathrm{SO}_{2}$ (dashed lines) and particulate sulfate (solid lines) burdens after a simulated volcanic eruption in July compared to sulfate observations from HIRS satellite after the 1991 Pinatubo eruption (black). (b) Zonal mean effective radius at $53^{\circ} \mathrm{N}$ latitude after the simulated July eruption compared to lidar measurements at Laramie $41^{\circ} \mathrm{N}$ (dots) and Geesthacht $53^{\circ} \mathrm{N}$ (crosses) after the Pinatubo eruption (Ansmann et al., 1997). In both panels the results are shown for altitude range $16-20 \mathrm{~km}$. The different coloured lines show results from the five members of the simulated ensemble (simulations Volc1, .., Volc5).
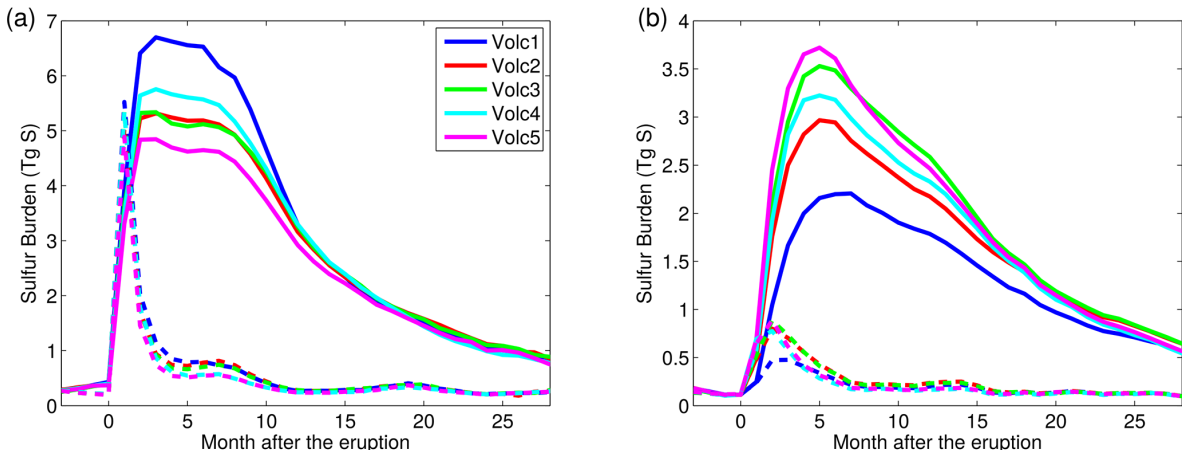

Figure A2. $\mathrm{SO}_{2}$ (dashed lines) and sulfate (solid lines) burden after the eruption on (a) Northern Hemisphere and (b) Southern Hemisphere Note different the scales on the $y$ axes.
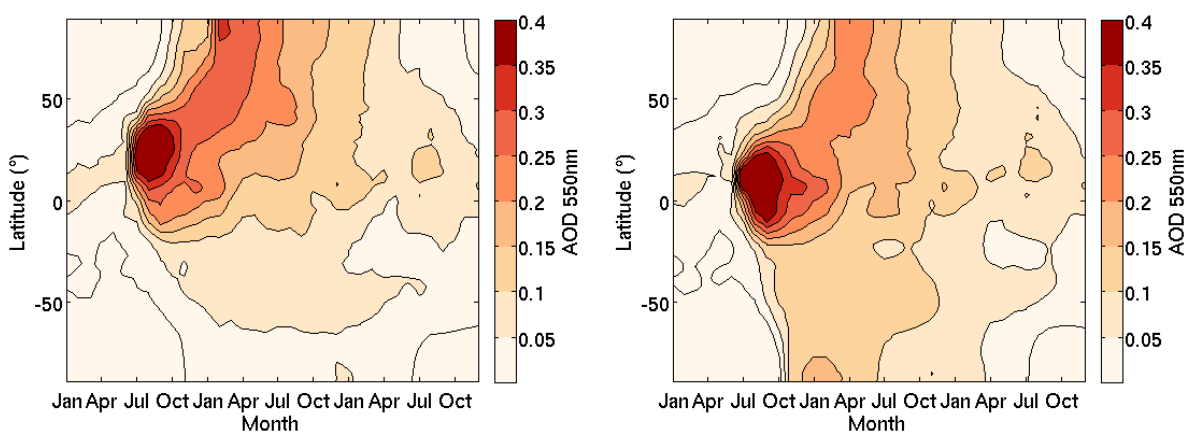

Figure A3. Zonal and monthly mean $550 \mathrm{~nm}$ aerosol optical depth after volcanic eruption in (a) Volc1 simulation and (b) Volc5 simulation. 


\section{Appendix B: Sensitivity simulations: location and season of the eruption}

\section{B1 Description of sensitivity runs}

We also performed a set of sensitivity simulations to investigate how the season and location of the volcanic eruption during SRM impacts the global sulfate burden and radiative forcing. The baseline scenario SRM Volc was compared with three new simulations summarized in Table B1 and detailed below. These sensitivity runs were performed only using MAECHAM5-HAM-SALSA due to the high computational cost of the full ESM, and are therefore limited to analysis of sulfur burdens and radiative forcings.

In the baseline simulations the eruption took place in the Tropics. Because the predominant meridional transport in the stratosphere is from the Tropics towards the poles, sulfur released in the Tropics is expected to spread throughout most of the stratosphere. On the other hand, sulfate released in the mid- or high latitudes will spread less effectively to the lower latitudes, and an eruption at mid- or high latitudes will therefore lead to more local effects in only one hemisphere. Therefore we conducted a sensitivity run simulating a July eruption during SRM at Mount Katmai (Novarupta) $\left(58.2^{\circ} \mathrm{N}, 155^{\circ} \mathrm{W}\right)$ where a real eruption took place near the northern arctic area in year 1912 (simulation SRM Arc July).

The local stratospheric circulation patterns over the eruption site will also affect how the released sulfur will be transported. Furthermore, stratospheric circulation patterns are dependent on the season and thus sulfur transport and subsequent climate effects can be dependent on the time of the year when the eruption occurs. For example, the meridional transport toward the poles is much stronger in the winter than in the summer hemisphere (Fig. B1). For this reason, we repeated both the tropical and the Arctic volcanic eruption scenarios assuming that the eruption took place in January instead of July (SRM Volc Jan and SRM Arc Jan, respectively).

\section{B2 Results from sensitivity simulations}

Figure B2 shows that the season of the tropical eruption does not significantly affect the stratospheric sulfate burden or the global mean clear-sky radiative forcing (simulations SRM Volc and SRM Volc Jan). The difference in peak burden values between the simulations with January and July eruptions is under $1 \%(0.11 \mathrm{Tg}(\mathrm{S}))$ and in peak clear-sky forcing about $1 \%$. Although the timing of the eruption does not have a large impact on the global mean values, there is some asymmetry between the hemispheres as peak value of additional sulfate from the eruption is $54 \%$ larger after the tropical $\mathrm{NH}$ eruption in July (boreal summer) than in January (boreal winter) (not shown). This is because the predominant meridional wind direction is towards the south in July and towards the north in January (Fig. B1). Our results are consistent with previous studies (Toohey et al., 2011; Aquila et al., 2012)

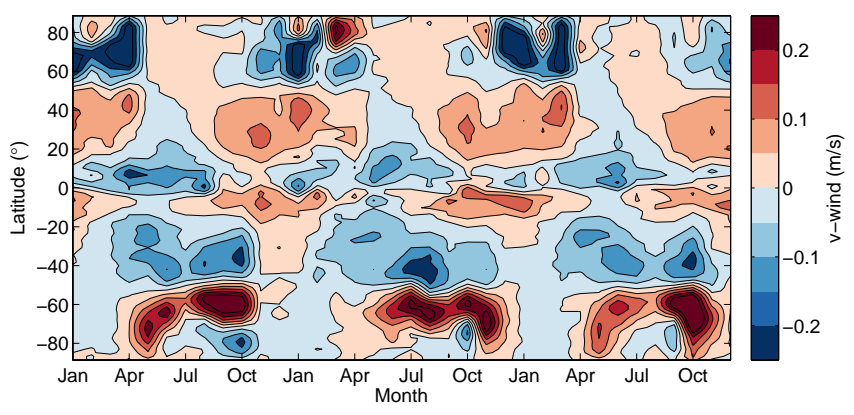

Figure B1. Meridional wind components (positive values from south to north) at $25 \mathrm{~km}$ altitude in CTRL simulation with MAECHAM5-HAM-SALSA.

which showed that a Pinatubo type tropical eruption in April would lead to an even increase in AOD in both hemispheres, while a volcanic eruption during other seasons will lead to more asymmetric hemispheric forcings. We show that these results hold also if the eruption takes place during SRM.

On the other hand, if the eruption takes place in the Arctic, the season of the eruption becomes important. Figure B2a shows that a summertime Arctic eruption (SRM Arc July) leads to similar global stratospheric peak sulfate burden as the tropical eruptions (SRM Volc Jan and SRM Volc), although the burden declines much faster after the Arctic eruption. However, an Arctic eruption in January (SRM Arc Jan) leads to a global stratospheric sulfate burden peak value that is only $\sim 82 \%$ of the July eruption value. The peak value is also reached 2 months later in the January eruption. Regarding the global forcing (Fig. B2b), an Arctic winter-time eruption (SRM Arc Jan) leads to a very similar peak forcing than the tropical eruptions, while the additional peak forcing (compared to the pre-eruption level) is $38 \%$ lower if the Arctic eruption takes place in July.

It is interesting to note that in the case of the Arctic volcano, a July eruption leads to a clearly higher stratospheric sulfate peak burden than the January eruption, but the opposite is true for global peak forcing (Fig. B2). A major reason for this is the strong seasonal variation in available solar radiation and subsequent hydroxyl radical $(\mathrm{OH})$ concentration in the high latitudes. $\mathrm{OH}$ is the main oxidant that converts $\mathrm{SO}_{2}$ to sulfuric acid $\left(\mathrm{H}_{2} \mathrm{SO}_{4}\right)$. Due to the rising $\mathrm{OH}$ concentrations in the Arctic spring, the peak in sulfur burden in the January eruption is reached during the Arctic summer when there is highest amount of sunlight available to be reflected back to space. However, when the eruption takes place in July, the peak burden is reached already in October due to high $\mathrm{OH}$ concentrations, and thus much faster compared to the winter-time eruption. However, when the peak value is reached, the intensity of solar radiation has already dramatically decreased, and thus the peak radiative forcing from the eruption remains small. The fast conversion of $\mathrm{SO}_{2}$ to sulfate also leads to larger particles than after the winter eruption 
Table B1. Sensitivity scenarios run only with MAECHAM5-HAM-SALSA. Here Jan refers to a volcanic eruption in January and Arc to an Arctic eruption at the site of Katmai.

\begin{tabular}{llll}
\hline Scenario & Timing of eruption & Eruption site & SRM \\
\hline SRM Volc Jan & 1 January & Pinatubo $\left(15^{\circ} \mathrm{N}, 120^{\circ} \mathrm{E}\right)$ & suspended \\
SRM Arc Jan & 1 January & Katmai $\left(58^{\circ} \mathrm{N}, 155^{\circ} \mathrm{W}\right)$ & suspended \\
SRM Arc July & 1 July & Katmai $\left(58^{\circ} \mathrm{N}, 155^{\circ} \mathrm{W}\right)$ & suspended \\
\hline
\end{tabular}
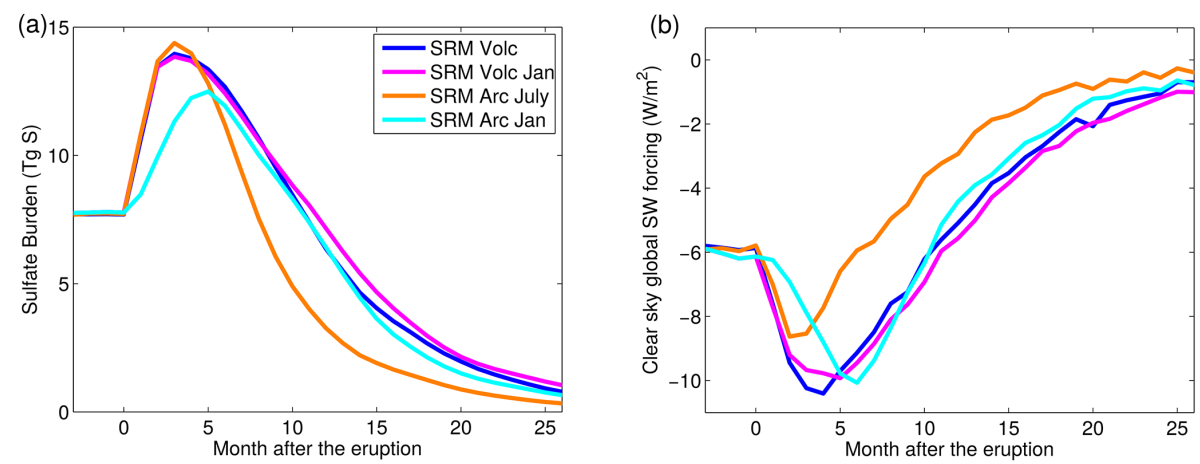

Figure B2. (a) Stratospheric sulfate burden and (b) global mean clear-sky shortwave radiative forcing after the eruption in January (blue line) and July (magenta line) and Arctic eruption in January (cyan line) and July (orange line).

and consequently to faster sedimentation and shorter lifetime (Fig. B2a).

Another main factor that has impact on the climate effects of an Arctic eruption is the stratospheric circulation. Concurrent circulation patterns can influence the sulfate lifetime and radiative effects. As Fig. B1 shows, there is a strong seasonal cycle in the Arctic meridional winds. If an Arctic volcano erupts in January, strong zonal polar vortex winds block poleward transport of released sulfur and it can spread towards midlatitudes. In contrast, in July the atmospheric flow is towards the north at the northern high latitudes (Fig. B1) and the sulfur stays in the Arctic. At the same time seasonality of subtropical barrier affects how sulfate is transported to the Tropics. As Fig. B1 shows, winds in the northern border of the Tropics are towards the south only between April and July and sulfur is transported to the Tropics only dur- ing this time period. There is clearly more sulfate at the northern border of the Tropics during these months after the Arctic eruption in January, while most of the sulfate is already removed from the atmosphere if the volcano erupted in July. Thus 6 months after the Arctic eruption, the stratospheric sulfur burden in the Tropics between $30^{\circ} \mathrm{N}$ and $30^{\circ} \mathrm{S}$ is $3.1 \mathrm{Tg}(\mathrm{S})$ for a July eruption but $4.2 \mathrm{Tg}(\mathrm{S})$ for a January eruption. Since the Tropics have much more solar radiation for the sulfate particles to scatter than the higher latitudes, part of the stronger radiative forcing in the SRM Arc Jan simulation compared to SRM Arc July (Fig. B2b) arises from this difference in transport to the Tropics. Furthermore, since the lifetime of sulfur is longer in the low than in the high latitudes, this leads to a longer average sulfur lifetime in the SRM Arc Jan simulation (Fig. B2a). 
Acknowledgements. This work was supported by the Academy of Finland's Research Programme on Climate Change (FICCA) (project 140867), Academy of Finland's Centre of Excellence Programme (decision 272041), Maj and Tor Nessling Foundation (grant 2012116), and the Academy of Finland's Academy Research Fellow position (decision 250348). The authors wish to thank T. Bergman and S. Rast for technical assistance with the models, A. Karpecho for helpful discussions related to stratospheric dynamics and T. Kühn for discussions related to using coupled models and A. Baran for comments concerning about HIRS data. The ECHAM-HAMMOZ model is developed by a consortium composed of ETHZ, Max Planck Institut für Meteorologie, Forschungszentrum Jülich, University of Oxford and the Finnish Meteorological Institute and managed by the Center of Climate Systems Modeling (C2SM) at ETHZ.

Edited by: J.-U. Grooß

\section{References}

Ansmann, A., Mattis, I., Wandinger, U., Wagner, F., Reichardt, J., and Deshler, T.: Evolution of the pinatubo aerosol: raman lidar observations of particle optical depth, effective radius, mass, and surface area over central europe at 53. $4^{\circ}$ N, J. Atmos. Sci., 54, 2630-2641, doi:10.1175/15200469(1997)054<2630:EOTPAR>2.0.CO;2, 1997.

Aquila, V., Oman, L. S., Stolarski, R. S., Colarco, P. R., and Newman, P. A.: Dispersion of the volcanic sulfate cloud from a Mount Pinatubo-like eruption, J. Geophys. Res., 117, D06216, doi:10.1029/2011JD016968, 2012.

Bala, G., Duffy, P. B., and Taylor, K. E.: Impact of geoengineering schemes on the global hydrological cycle, P. Natl. Acad. Sci. USA, 105, 7664-7669, doi:10.1073/pnas.0711648105, 2008.

Baran, A. J. and Foot, J. S.: New application of the operational sounder HIRS in determining a climatology of sulphuric acid aerosol from the Pinatubo eruption, J. Geophys. Res.-Atmos., 99, 25673-25679, 1994.

Bergman, T., Kerminen, V.-M., Korhonen, H., Lehtinen, K. J., Makkonen, R., Arola, A., Mielonen, T., Romakkaniemi, S., Kulmala, M., and Kokkola, H.: Evaluation of the sectional aerosol microphysics module SALSA implementation in ECHAM5HAM aerosol-climate model, Geosci. Model Dev., 5, 845-868, doi:10.5194/gmd-5-845-2012, 2012.

Bony, S., Bellon, G., Klocke, D., Sherwood, S., Fermepin, S., and Denvil, S.: Robust direct effect of carbon dioxide on tropical circulation and regional precipitation, Nat. Geosci., 6, 447-451, 2013

Crutzen, P. J.: Albedo enhancement by stratospheric sulphur injections: A contribution to resolve a policy dilemma?, Climatic Change, 77, 211-219, 2006.

Dentener, F., Kinne, S., Bond, T., Boucher, O., Cofala, J., Generoso, S., Ginoux, P., Gong, S., Hoelzemann, J. J., Ito, A., Marelli, L., Penner, J. E., Putaud, J.-P., Textor, C., Schulz, M., van der Werf, G. R., and Wilson, J.: Emissions of primary aerosol and precursor gases in the years 2000 and 1750 prescribed data-sets for AeroCom, Atmos. Chem. Phys., 6, 4321-4344, doi:10.5194/acp-64321-2006, 2006.
Dhomse, S. S., Emmerson, K. M., Mann, G. W., Bellouin, N., Carslaw, K. S., Chipperfield, M. P., Hommel, R., Abraham, N. L., Telford, P., Braesicke, P., Dalvi, M., Johnson, C. E., O'Connor, F., Morgenstern, O., Pyle, J. A., Deshler, T., Zawodny, J. M., and Thomason, L. W.: Aerosol microphysics simulations of the Mt. Pinatubo eruption with the UM-UKCA composition-climate model, Atmos. Chem. Phys., 14, 11221-11246, doi:10.5194/acp14-11221-2014, 2014.

Driscoll, S., Bozzo, A., Gray, L. J., Robock, A., and Stenchikov, G.: Coupled Model Intercomparison Project 5 (CMIP5) simulations of climate following volcanic eruptions, J. Geophys. Res., 117, D17105, doi:10.1029/2012JD017607, 2012.

English, J. M., Toon, O. B., and Mills, M. J.: Microphysical simulations of sulfur burdens from stratospheric sulfur geoengineering, Atmos. Chem. Phys., 12, 4775-4793, doi:10.5194/acp-12-47752012, 2012.

English, J. M., Toon, O. J., and Mills, M. J.: Microphysical simulations of large volcanic eruptions: Pinatubo and Toba, J. Geophys Res.-Atmos., 118, 1880-1895, doi:10.1002/jgrd.50196, 2013.

Ferraro, A. J., Highwood, E. J., and Charlton-Perez, A. J.: Weakened tropical circulation and reduced precipitation in response to geoengineering, Environ. Res. Lett., 9, 014001, doi:10.1088/1748-9326/9/1/014001, 2014.

Fischer, E., Luterbacher, J., Zorita, E., Tett, S. F. B., Casty, C., and Wanner, H.: European climate response to tropical volcanic eruptions over the last half millennium, Geophys. Res. Lett., 34, L05707, doi:10.1029/2006GL027992, 2007.

Fuglestvedt, J. S., Samset, B. J., and Shine, K. P.: Counteracting the climate effects of volcanic eruptions using shortlived greenhouse gases, Geophys. Res. Lett., 41, 8627-8635, doi:10.1002/2014GL061886, 2014.

Giorgetta, M. A., Manzini, E., Roeckner, E., Esch, M., and Bengtsson, L.: Climatology and forcing of the quasi-biennial oscillation in the MAECHAM5 model, J. Climate, 19, 3882-3901, 2006.

Giorgetta, M. A., Jungclaus, J., Reick, C. H., Legutke, S., Bader, J., Böttinger, M., Brovkin, V.,Crueger, T., Esch, M., Fieg, K., Glushak, K., Gayler, V., Haak, H., Hollweg, H.-D., Ilyina, T.,Kinne, S., Kornblueh, L., Matei, D., Mauritsen, T., Mikolajewicz, U., Mueller, W., Notz, D., F., Raddatz, T., Rast, S., Redler, R., Roeckner, E., Schmidt, H., Schnur, R., Segschneider, J., Six, K. D., Stockhause, M., Timmreck, C., Wegner, J., Widmann, H., Wieners, K.-H., Claussen, M., Marotzke, J., and Stevens, B.:Climate and carbon cycle changes from 1850 to 2100 in MPI-ESM simulations for the coupled model intercomparison project phase 5, J. Adv. Model. Earth Syst., 5, 572-597, doi:10.1002/jame.20038, 2013.

Guo, S., Rose, W. I., Bluth, G. J. S., and Watson, I. M.: Particles in the great Pinatubo volcanic cloud of June 1991: The role of ice, Geochem. Geophy. Geosy., 5, Q05003, doi:10.1029/2003GC000655, 2004a.

Guo, S., Bluth, G. J. S., Rose, W. I., Watson, I. M., and Prata, A. J.: Re-evaluation of $\mathrm{SO}_{2}$ release of the 15 June 1991 Pinatubo eruption using ultraviolet and infrared satellite sensors, Geochem. Geophy. Geosy., 5, Q04001, doi:10.1029/2003GC000654, 2004b.

Hansen, J., Lacis, A., Ruedy, R., and Sato, M.: Potential climate impact of Mount-Pinatubo eruption, Geophys. Res. Lett., 19, 215 218, doi:10.1029/91GL02788, 1992. 
Heckendorn, P., Weisenstein, D., Fueglistaler, S., Luo, B. P., Rozanov, E., Schraner, M., Thomason, L. W., and Peter, T.: The impact of geoengineering aerosols on stratospheric temperature and ozone, Environ. Res. Lett. 4, 045108, doi:10.1088/17489326/4/4/045108, 2009.

Ilyina, T., Six, K. D., Segschneider, J., Maier-Reimer, E., Li, H., and Nunez-Riboni, I.: Global ocean biogeochemistry model HAMOCC: Model architecture and performance as component of the MPI-Earth System Model in different CMIP5 experimental realizations, J. Adv. Model. Earth Syst., 5, 287-315, doi:10.1029/2012MS000178, 2013.

IPCC: Climate Change 2013: The Physical Science Basis. Contribution of Working Group I to the Fifth Assessment Report of the Intergovernmental Panel on Climate Change, edited by: Stocker, T. F., Qin, D., Plattner, G.-K., Tignor, M., Allen, S. K., Boschung, J., Nauels, A., Xia, Y., Bex, V., and Midgley, P. M., Cambridge University Press, Cambridge, UK and New York, NY, USA, 1535 pp., doi:10.1017/CBO9781107415324, 2013.

Jungclaus, J. H., Fischer, N., Haak, H., Lohmann, K., Marotzke, J., Matei, D., Mikolajewicz, U., Notz, D., and von Storch, J.-S.: Characteristics of the ocean simulations in MPIOM, the ocean component of the MPI Earth System Model, J. Adv. Model. Earth Syst., 5, 422-446, doi:10.1002/jame.20023, 2013.

Keith, D. W. and MacMartin, D. G.: A temporary, moderate and responsive scenario for solar geoengineering, Nature Clim. Change, 5, 201-206, doi:10.1038/NCLIMATE2493, 2015.

Kinne, S., O’Donnell, D., Stier, P., Kloster, S., Zhang, K., Schmidt, H., Rast, S., Giorgetta, M., Eck, T. F., and Stevens, B.: MACv1: A new global aerosol climatology for climate studies, J. Adv. Model. Earth Syst., 5, 704-740, doi:10.1002/jame.20035, 2013.

Kokkola, H., Korhonen, H., Lehtinen, K. E. J., Makkonen, R., Asmi, A., Järvenoja, S., Anttila, T., Partanen, A.-I., Kulmala, M., Järvinen, H., Laaksonen, A., and Kerminen, V.-M.: SALSA - a Sectional Aerosol module for Large Scale Applications, Atmos. Chem. Phys., 8, 2469-2483, doi:10.5194/acp-8-2469-2008, 2008.

Kokkola, H., Hommel, R., Kazil, J., Niemeier, U., Partanen, A.-I., Feichter, J., and Timmreck, C.: Aerosol microphysics modules in the framework of the ECHAM5 climate model - intercomparison under stratospheric conditions, Geosci. Model Dev., 2, 97-112, doi:10.5194/gmd-2-97-2009, 2009.

Kravitz, B., Caldeira, K., Boucher, O., Robock, A., Rasch, P. J., Alterskjær, K., Karam, D., B., Cole, J. N. S., Curry, C. L., Haywood, J. M., Irvine, P. J., Ji, D., Jones, A., Kristjánsson, J. E., Lunt, D. J., Moore, J. C., Niemeier, U., Schmidt, H., Schulz, M., Singh, B., Tilmes, S., Watanabe, S., Yang, S., and Yoon, J.-H.: Climate model response from the Geoengineering Model Intercomparison Project (GeoMIP), J. Geophys. Res.-Atmos., 118, 8320-8332, doi:10.1002/jgrd.50646, 2013a.

Kravitz, B., Rasch, P. J., Forster, P. M., Andrews, T., Cole, J. N. S., Irvine, P. J., Ji, D., Kristjánsson, J. E., Moore, J. C., Muri, H., Niemeier, U., Robock, A., Singh, B., Tilmes, S., Watanabe, S., and Yoon, J.-H.: An energetic perspective on hydrological cycle changes in the Geoengineering Model Intercomparison Project, J. Geophys. Res.-Atmos., 118, 13087-13102, doi:10.1002/2013JD020502, 2013b.

Laakso, A., Partanen, A.-I., Kokkola, H., Laaksonen, A., Lehtinen, K. E. J., and Korhonen, H.: Stratospheric passenger flights are likely an ineffcient geoengineering strategy, Environ. Res. Lett., 7, 034021, doi:10.1088/1748-9326/7/3/034021, 2012.

McClellan, J., Keith, D. W., and Apt, J.: Cost analysis of stratospheric albedo modification delivery systems, Environ. Res. Lett., 7, 034019, doi:10.1088/1748-9326/7/3/034019, 2012.

Monahan, E., Spiel, D., and Davidson, K.: Oceanic whitecaps and their role in air-sea exchange, D. Reidel, Norwell, Mass., USA, 167-174, 1986.

Niemeier, U. and Timmreck, C.: What is the limit of climate engineering by stratospheric injection of $\mathrm{SO}_{2}$ ?, Atmos. Chem. Phys., 15, 9129-9141, doi:10.5194/acp-15-9129-2015, 2015.

Niemeier, U., Timmreck, C., Graf, H.-F., Kinne, S., Rast, S., and Self, S.: Initial fate of fine ash and sulfur from large volcanic eruptions, Atmos. Chem. Phys., 9, 9043-9057, doi:10.5194/acp9-9043-2009, 2009.

Niemeier, U., Schmidt, H., and Timmreck, C.: The dependency of geoengineered sulfate aerosol on the emission strategy, Atmos. Sci. Lett. 12, 189-194, 2011.

Niemeier, U., Schmidt, H., Alterskjær, K., and Kristjánsson, J. E.: Solar irradiance reduction via climate engineering: Impact of different techniques on the energy balance and the hydrological cycle, J. Geophys. Res., 118, 12195-12206, 2013.

Pierce, J. R., Weisenstein, D., Heckendorn, P., Peter, T., and Keith D. W.: Efficient formation of stratospheric aerosol for climate engineering by emission of condensible vapor from aircraft, Geophys. Res. Lett., 37, L18805, doi:10.1029/2010GL043975, 2010.

Rasch, P. J., Tilmes, S., Turco, R. P., Robock, A., Oman, L., Chen, C.-C., Stenchikov, G. L., and Garcia, R.: An overview of geoengineering of climate using stratospheric sulphate aerosols, Phil. T. R. Soc. A, 366, 4007-4037, 2008.

Read, W. G., Froidevaux, L., and Waters, J. W.: Microwave limb sounder measurements of stratospheric $\mathrm{SO}_{2}$ from the Mt. Pinatubo volcano, Geophys. Res. Lett., 20, 1299-1302, 1993.

Reick, C., Raddatz, T., Brovkin, V., and Gayler, V.: The representation of natural and anthropogenic land cover change in MPI-ESM, J. Adv. Model. Earth Syst., 5, 459-482, doi:10.1002/jame.20022, 2013.

Robock, A.: Volcanic eruptions and climate, Rev. Geophys., 38, 191-219, doi:10.1029/1998RG000054, 2000.

Robock, A. and Mao, J.: Winter warming from large volcanic eruptions, Geophys. Res. Lett., 19, 2405-2408, 1992.

Robock, A., Marquardt, A., Kravitz, B., and Stenchikov, G.: Benefits, risks, and costs of stratospheric geoengineering, Geophys. Res. Lett., 36, L19703, doi:10.1029/2009GL039209, 2009.

Schulz, M., de Leeuw, G., and Balkanski, Y.: Sea-salt aerosol source functions and emissions, in: Emission of Atmospheric Trace Compounds, Kluwer Acad., Norwell, Mass., USA, 333359, 2004.

Sheng, J.-X., Weisenstein, D. K., Luo, B.-P., Rozanov, E., Arfeuille, F., and Peter, T.: A perturbed parameter model ensemble to investigate Mt. Pinatubo's 1991 initial sulfur mass emission, Atmos. Chem. Phys., 15, 11501-11512, doi:10.5194/acp15-11501-2015, 2015.

Smith, M. and Harrison, N.: The sea spray generation function. J. Aerosol Sci., 29, 189-190, 1998.

Stenchikov, G., Delworth, T. L., Ramaswamy, V., Stouffer, R. J., Wittenberg, A., and Zeng, F.: Volcanic signals in oceans, J. Geophys. Res., 114, D16104, doi:10.1029/2008JD011673, 2009. 
Stevens, B., Giorgetta, M., Esch, M., Mauritsen, T., Crueger, T., Rast, S., Salzmann, M., Schmidt, H., Bader, J., Block, K., Brokopf, R., Fast, I., Kinne, S., Kornblueh, L., Lohmann, U., Pincus, R., Reichler, T., and Roeckner, E.: The atmospheric component of the MPI-M Earth System Model: ECHAM6, J. Adv. Model. Earth Syst., 5, 1-27, doi:10.1002/jame.20015, 2013.

Stier, P., Feichter, J., Kinne, S., Kloster, S., Vignati, E., Wilson, J., Ganzeveld, L., Tegen, I., Werner, M., Balkanski, Y., Schulz, M., Boucher, O., Minikin, A., and Petzold, A.: The aerosol-climate model ECHAM5-HAM, Atmos. Chem. Phys., 5, 1125-1156, doi:10.5194/acp-5-1125-2005, 2005.

Tegen, I., Harrison, S. P., Kohfeld, K., Prentice, I. C., Coe, M., and Heimann, M.: Impact of vegetation and preferential source areas on global dust aerosol: Results from a model study, J. Geophys. Res., 107, 4576, doi:10.1029/2001JD000963, 2002.
Timmreck, C.: Modeling the climatic effects of volcanic eruptions, Wiley Interdisciplinary Reviews: Climate Change, 3, 545-564, doi:10.1002/wcc.192, 2012.

Timmreck, C., Graf, H.-F., and Kirchner, I.: A one and a half year interactive simulation of Mt. Pinatubo aerosol, J. Geophys. Res., 104, 9337-9360, 1999.

Timmreck, C., Graf, H.-F., Lorenz, S. J., Niemeier, U., Zanchettin, D., Matei, D., Jungclaus, J. H., and Crowley T. J.: Aerosol size confines climate response to volcanic super-eruptions (2010), Geophys. Res. Lett., 37, L24705, doi:10.1029/2010GL045464, 2010.

Toohey, M., Krüger, K., Niemeier, U., and Timmreck, C.: The influence of eruption season on the global aerosol evolution and radiative impact of tropical volcanic eruptions, Atmos. Chem. Phys., 11, 12351-12367, doi:10.5194/acp-11-12351-2011, 2011. 